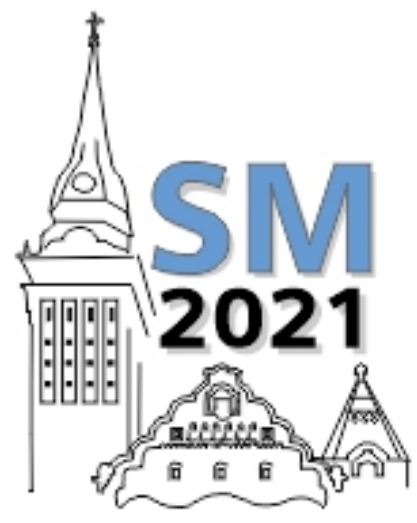

26th International Scientific Conference

Strategic Management and Decision Support Systems in Strategic Management

21st May, 2021, Subotica, Republic of Serbia

\author{
Robert Dobó \\ Budapest Business School, University of Applied Sciences \\ Faculty of Commerce, Hospitality and Tourism \\ Department of Economics and Business Studies \\ dobo.robert@uni-bge.hu
}

\title{
SOURCE PRESTIGE IN COVID-19 COMMUNICATION
}

\begin{abstract}
In line with present global events, governmental and public service communication faces new challenges, which include spreading misinformation, ineffectiveness of communication practices and public insecurity. Governments and health officials during pandemics have been criticised for less than optimal communication practices in the past, not in line with public preferences. In communication theory, information is viewed through double glasses, which includes the spokesperson, and the chosen communication channel. Good practices are able to harness the synergies of these two factors. In this article, the credibility and popularity of communication channels are analysed, namely focusing on public preference, source prestige and source power. At the same time public trust scores are gathered about different professions, to evaluate public preferences. The primary research data suggests that the public is generally unsure about the credibility of governmental public news sources, similarly about those channels, like television networks that are publicly owned or administered. At the same time, there is a clear preference for online channels, with social media becoming more and more influential and popular. The research findings conclude that members of the "Millennial" and "Generation Z" groups expect most credible communication to come from nongovernmental and non-political sources. Regarding the profession of the influencer or spokesperson distributing information, they prefer two-way communication, and distinguish between professions, assign clear differences in credibility. One of the most interesting findings was, that a person's profession, for example healthcare professional, has a positive effect on credibility, but this effect is only present, until the public doesn't consider the person politically affiliated, thus referring to them as "politicians". In these cases, regardless of their original profession, the credibility and trust score is substantially lowering.
\end{abstract}

Keywords: Credibility, Trust, Popularity, Marketing Communication Channels, Covid19, Source Prestige, Opinion leader

\section{Introduction:}

There is an ongoing evolution of marketing communication, the form and channels are changing, and evidently this change is affiliated with technological advances. During this evolution, the emergence of disruptive technologies are more and more frequent, smart phones changed communication practices (Keegan and Green, 2011). A new form, social media communication has emerged, which can be understood as an extension of word of mouth communication, thus organisations are seeking to influence these networking practices of the general public (Hollensen, 2011). Classical channels are not disappearing, but are steadily losing ground in line with new, mainly online based channels (Orosdy and Dobó; 2018). Considering the market trends, the proliferation of the internet causes people to be connecting globally, without the limiting factors of time and geographic location. Considering the households using the internet, there is a steady growth. In Europe, digitalization is growing, the amount of households using the internet has grown by $10 \%$ during the past 5 years, from $80 \%$ on average in 2014 to $90 \%$ in 2019 in the EU27 zone (Eurostat, 2019), the lowest on the continent being in Bosnia and Herzegovina, Montenegro and Bulgaria, respectively 72-74-75\% in 2019. With the internet, came social media and the possibility for networking and finding common interests. These social 
media sites have global reach, currently Facebook being the leader with 2,7 billion active users, followed by YouTube with over 2,2 and Instagram with 1,2 billion active users (Statista, 2021). Similarly high number of users is visible when considering messaging application, such as WhatsApp, Messenger with 2 and 1,3 billion users respectively. Other global players include Snapchat (498 million) and TikTok (689 million), both outperforming Twitter (353 million).

With this evolution came the evolution of marketing. During the 1950's, a change in focus was evident, moving away from the product and service, to the customer and their decision making processes (Lemon and Verhoef, 2016). This was further developed by the emergence of new technologies and processes, mainly information gathering and analysing through information technology and the internet. Today organisations use CRM (Cusromer Relationship Management) and CEM (Customer Experience Management) software to gather information, pinpoint out interaction points and further develop their operations (Mayer and Schwager, 2007; Rawson et al., 2013), thus gathering historical and real time data. In regards to public organisations, the same practices should be utilized, to ensure the same results as professional private organisations are experiencing.

Why is it important to follow public trends and changes? Previous global event, such as the MERS outbreak in South Korea during 2015, demonstrated the adverse effects of the lack of public trust towards public health officials (PHO). This involved a high level of uncertainty, changes in favour of online and social media communication, withholding information from the public, or not meeting the general publics need (Jang and Baek, 2019). To fulfil this informational need, people focused on online news and interpersonal networks, such as social media. The aforementioned article determined that there is a negative correlation between PHO source credibility and usage of online news, meaning, the less credible the information was perceived, the more the public preferred using online sources for finding crisis-related information. The European Centre for Disease Prevention (ECDC, 2012) outlines the importance of trust and transparency of PHO communication, with a focus on trustworthy and evidence based information. It outlines the need for public education to decrease public insecurities. It encourages two-way communication for meaningful dialogue, and draws the attention to the different segments of the population perceiving communication channel trust and credibility according to their preferences. It also outlines the risk of online and social media communication, because, regardless of the accuracy of the information, it is still the most convenient, most used and accessible channel.

\subsection{Governments and new media:}

This also provides opportunities, as governmental organisations use more and more social media, in a new way of engagement. One of these opportunities arise during crisis management. Social media helps coordinate efforts, it enables people to gather and self-organise (Harlow, 2013). The most effective use for social media comes in warning activities through content creation, observing happenings and listening to trends (Carter, Thatcher and Wright, 2014). Gathering information about the accuracy of the information, a study found alarming level of misinformation about the Covid19 pandemic through online and social media outlets, with an analysis of Twitter tweets. At cases, more of the combined tweets were misinformation, than the news aimed at combatting these conspiracies. At the same time, public health recommendations clearly focused on classical channels, thus not enough energy was diverted to social media (Bridgman et. al. 2020). This was more evident in online than traditional media, probably because of the low entry barriers on social networking sites. A similar study done in Poland also found alarmingly high rates of medical related fake news, at some cases 9 out of 10 shared links on social media (majority on facebook) about the vaccination was fake news (Waszak et. al. 2018).

\subsection{Research questions:}

In line with the ongoing public health crisis, caused by Covid19, the aim of the article is to:

a) Examine the credibility and popularity of different communication channels,

b) Examine the effect a person's profession has on public trust on information shared,

c) Identify possible synergies between the two, which enables PHO and other governmental organisations in battling fake news and efficiently communicating public service news in a credible form.

\section{Methodology:}

The reasoning of the article is inductive. During the research, a mixed methods approach was chosen, thus the primary research used both qualitative and quantitative data.

Qualitative data has been obtained in the form of a focus group interview, with a sample of 8, involving public health workers and marketing professionals. The goals was to gain an in-depth understanding of the issue of public trust and communication preferences, with the help of open ended questions, in the form of a semi structured interview. 
Quantitative data has been gathered through a questionnaire, involving a sample of 732 responses, gathered cumulatively during three separate occasions in 2018, 2019 and 2021. This data vas transcribed with Microsoft Excel 2013 and cross section analysed with SPSS 24. During the three collecting occasions, 169, 287 and 276 respondents participated. During the survey closed ended, multiple choice and 6 point likert scale questions were used.

Secondary data has been obtained through reviewing related scientific literature and statistics.

\subsection{Limitations and ethical considerations:}

Data collection was prevented during 2020 because of the pandemic. The 2018 and 2019 surveys were in person, the 2021 was performed online, Google documents were used, distributed in closed groups of students. Young adults were in the focus of the research, mainly university students (Budapest Business School, University of Pécs, Corvinus University, University of Debrecen, University of Szeged and ELTE), thus the collected data is indicative, representing the preferences of the Millennials and Generation Z. During the focus group interviews, the anonymity of the participants was an important factor.

\section{Source prestige, source power and credibility}

Source prestige is defined by the rank of the communication channel in the eyes of the public, thus how credible and trusted is the source. Source power describes the size of the channel, thus how great of an audience it can reach. Another factor is the credibility of the person, sending the message. Source prestige, combined with the person will determine the overall credibility of the information (Tóth, 2009). Good communication practices combine all three, thus creating synergies. The research of Heideker and Steul-Fischer (2017) underpins this notion, as they find strong correlation between credibility and the influence of the source based trust mark, when examining ad credibility on health risk perception. Credibility has three cornerstones: a) reliability and trustworthiness, b) expertise in the subject and c) attractiveness valued by sympathy (Maathuis, Rodenburg and Sikkel, 2004). In their study, they also examined governmental organisations, and in general found that positive evaluations are cognitive (deeper understanding), while negative are affective (feelings). Governmental organisations should focus on alternative channels, as information can be manipulated and tailored, according to their needs. According to some estimates, online advertising involved 327 billion US dollars during 2019, whit some major players being Google and Fecebook, that have clear algorithms and surveillance information, thus these platforms have a better understanding on user preferences. This includes micro targeting and a wide range of adaptation and tailoring practices, thus optimise persuasive power (Crain and Nadler, 2019).

Credibility can be understood as the perception of the source, thus having relevant expertise to the topic and an objective opinion that builds trust. Credibility is strongly correlating with the attitude towards the given brand (Goldsmith et. al. 2000). In public service communication, this branding can be understood as the credibility of the organisation. For example if the spokesperson of the National Ambulance Service were to give a statement, in this case the public will first review its trust towards the organisation itself. Than secondly determine if the spokesperson is capable of building trust through objective and appropriate communication. Thus the public will combine the two and evaluate the overall credibility.

In this aspect, credibility is a multidimensional concept, thus more dimensions have to be considered when analysing it (Elsend, 2006). This credibility can be measured, referring to McGuire, through the 13 step Communication-Persuasion matrix, that encompasses the source, the message, the receiver, the channel etc. (Schmidt, et. al. 2016).

Thus, in line with the literature, source prestige can be understood as a multidimensional framework, which is influenced by the credibility of the: 1) source, 2) communication channel, 3) person delivering the message, and 4) brand.

\section{Personal Credibility and Opinion Leaders}

Key barriers are present in public communication, namely verbal ones (using terms and expressions that make the language too technical), non-verbal ones (body language) and external interruptions (any kind of noise that has a negative influence). Thus credibility and trust is affected by "the body language, tone and intonation, words and discourse structure" (Busa et. al. 2015). There are no clearly defined traits that differentiate an opinion leader and followers, but a mix of continuous traits that differentiate (Gnambs, 2019).

When communicating, the socio-cultural aspects, demographics, media habits and personalities of the receiver should be considered. This, compared with a capable opinion leader, can have great influence. Opinion leaders have product 
familiarity, personal involvement, and public individuation (Chan and Misra, 1990). Opinion seekers are influenced by opinion leaders, who are use a variety of communication channels, including on and offline channels, word of mouth etc. Opinion seekers are confronted with objective (truly process and can demonstrate) and subjective knowledge (beliefs and perception, emotions). In correlation to opinion leaders, in their study, Vigar-Ellis, Pitt and Caruana (2015) found that there is a negative correlation between opinion leaders and objective knowledge. Thus, although opinion leaders have a great influence, data shows that in general they are not necessarily more knowledgeable than ordinary opinion seekers. This is partially in contrasts with an earlier study that shows that opinion leaders generally use higher quality information sources (Roch, 2005). There is also a negative correlation between trust and opportunistic behaviour, and in general there is a positive relationship between trust and cooperation (Morgan and Hunt, 1994).

According to Midgley and Dowling's (1978) and opinion leaders holds favourable views toward a product, (or in this case a public health issue), but must also be willing to clearly communicate this position towards the public. A study of Spanish opinion leaders during the 2019 election shows, that the majority of influencer online social media communication is the extension of their classical channels, providing news, new data and breaking news (MarcosGarcia et. al, 2020). Criticizing and reflecting on policies were second and third, and interaction fourth among 12 factors. Thus, this study also reflects on the importance on social media communication, when extending classical options.

According to the literature, it can be stated than, a successful opinion leader expresses thoughts in a credible way, if: a) verbal and non-verbal attributes are in line with public expectations, b) they are familiar and have expertise in the subject, c) use the appropriate communication channel, d) they are not opportunistic and e) use a wide range of communication channels, including online ones, focusing on social media as it is becoming more and more preferred.

\section{Primary Research:}

The collected data from the primary questionnaire study has been transcribed with Microsoft Office Excel 2013, and the data has been analysed using SPSS 24. Descriptive statistics, mean, average and ANOVA tables, Kaiser-Meyer-Olkin (KMO) test for sampling adequacy, a Pearson Correlation and a Covariance test have been performed.

\subsection{General Research Data:}

For channel credibility, the participants were asked, to indicate on a 6 point likert scale (1 indicating no, and 6 indicating maximum trust) their sentiment towards seven communication channels (see figure 1). For channel preference, the participants used the same 6 point likert scale, but they had to determine a preference scale between six communication channels (see figure 2), thus one number could only be assigned to one channel. This means that on the credibility scale, two or more channels can have the same credibility score, but in the preferential order, they cannot. In the case of profession credibility, the aforementioned 6 point likert scale was used for 8 (in 2021 for ten) professions (see figure 3).

The focus group interview took place online, with 8 participants. They were contrasted with the findings and open ended questions for deeper understanding.

\subsection{General Statistical Data:}

For the communication channel credibility, the KMO test showed on the whole dataset $(n=732)$ a 0,742 value, that indicates that the sampling is adequate. Covariance was positive throughout the sample, all correlation values given the seven variables were significant at the 0.01 level. All values were between 1 and 6 , with standard deviation being between 1,06 and 1,22, no outlying variable can be identified. Correlation values show a wide range between 0,074 and 0,606 being generally weak and medium. The strongest between internet and social media $(0,606)$, the second between governmentally owned or administered television and classical channels such as radio and newspaper (487) and third mass media in general and classical channels (440). All other were below 0,400. For the communication channel preference, all values were between 1 and 6, standard deviation between 1,21 and 1,51 with no outlying value, covariance was mixed throughout the sample. Correlations were in general negative and low, the strongest correlation (0,427 at a 0,01 level) between governmental news channels and online channels, all other were weak below 0,300 . An interesting finding was, that no significant correlation was found between online channels and social media $(0,058)$, thus indicating that the participants don't consider social media to be one of the online channels, but to be a separate one. In the case of profession credibility, all values were between 1 and 6 except in the case of those working in Politics, where no value 6 was found in the whole sample, the maximum being 5 . Standard deviation was between 0,85 and 1,19 with no outliers. Except for "Family and Friends" and "Politics", where covariance was negative, all other cases were positive. Correlation was medium to weak, strongest in the case of "television personalities" and "musicians 
and entertainers" $(0,542)$, second between persons working in "economics and law" and "engineering" $(0,480)$, and third education and healthcare $(0,389)$ all three at a 0,01 significance level.

\section{Findings and Discussion:}

The data of the primary research was gathered and the interview and questionnaire findings were cross analysed. The following section focuses on three fields (Channel credibility, channel preference and profession credibility) and describes the findings of the primary research.

\subsection{Source Credibility:}

Figure 1 shows the seven communication channels analysed. The three data collecting occasions were analysed separately, the channel credibility scores were taken into consideration and averages were computed. Table 1 shows the averages of each communication channels. Not surprisingly "Family and Friends" has the highest credibility score, thus is the most trusted communication channel. Although there are slight variations in the yearly averages, there is no change in the credibility order.

Given the 2021 data, there is a negative trend visible in social media and internet trust and a growing trend in the trust of information coming from "Family and Friends". According to the focus group interview, this mistrust can come, given the low entry barriers, the general lack of proof reading and checking, and from the sheer amount of fake information coming from these online sources. It should be noted, that the public least trusts governmental news sources, and generally mistrusts mass media. Further and detailed yearly average scores are visible in Table 1 . This in part can be the effect of the one-sided governmental communication practices, that isn't in line with the preferences of those participating. This notion was validated by the group interview. The higher the control over it, the least trustworthy the information is, this same is visible when asking about interaction, a) the more uncontrolled and two-way interaction is possible, b) the higher the freedom of asking questions and information is, the more are the answers and statements in turn, deemed as true and trustworthy.

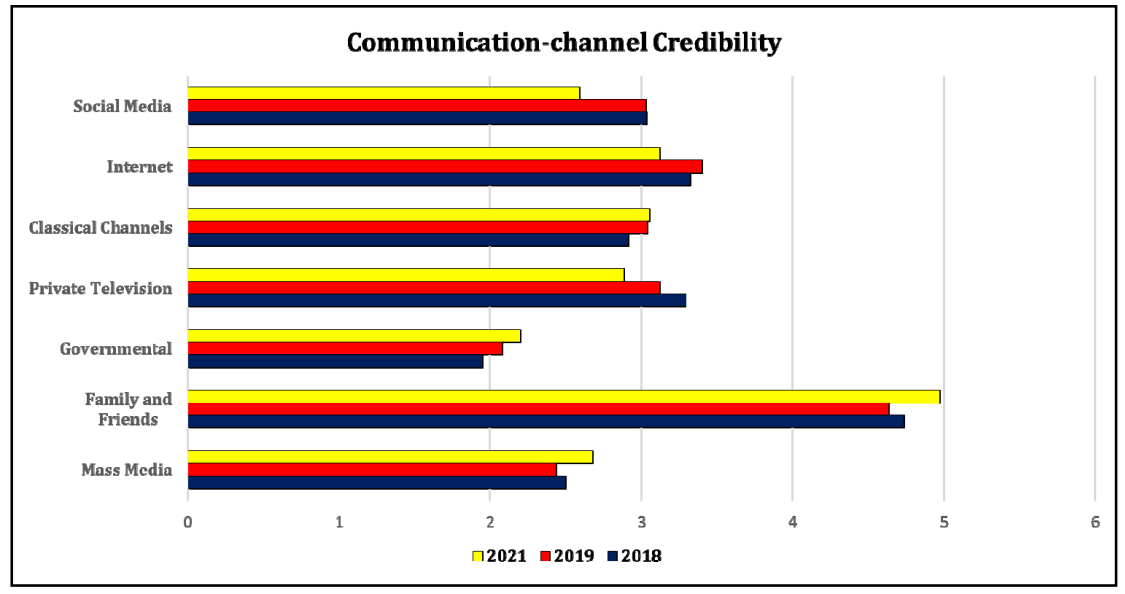

Figure 1. Yearly Communication-channel Credibility scores. Source: Based on primary research.

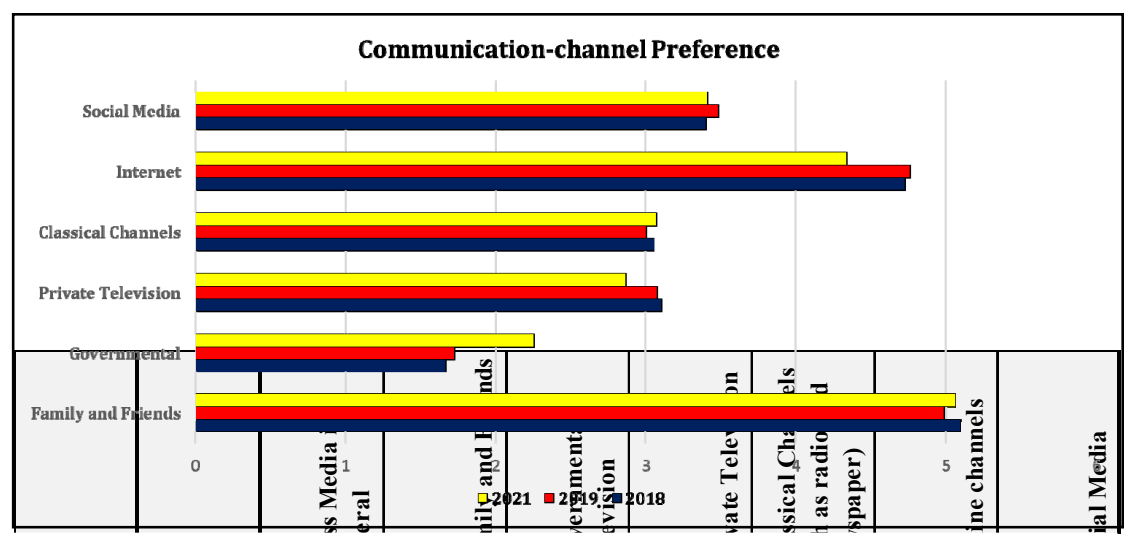

Figure 2. Yearly Communication-channel Preference scores. Source: Based on primary research.

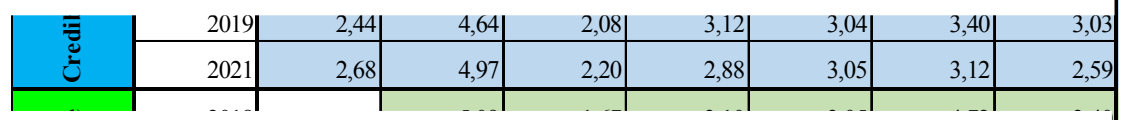

Table 1. Deataled averages of yearly communication-channel credibility and preference scores. Source: Based on primary research.

\subsection{Source Preference:}

Figure 2. shows the preferential order of the six communication channels. As aforementioned, the same trust score can be given to two or more channels, but in regards to the preferential order, a clear distinction had to be made. Although here are yearly variations in the averages, still no change in the preferential order is visible. Family and Friends is the first place. This was expected, given the proximity. Second are online sources and third social media. The interview subjects explained this to be cause by the general ease of use, easy access and wide availability. If considering social media, the number of users is a good indicator, why people try to gather information through it. It's quick, free and as more and more people are interconnected, groups are formed that can exchange ideas, experiences without the limiting factor of geography.

There were two evident changes in the data, namely the preference of the internet dropped, and the Governmental sources grew. 
According to the interview, this is most likely a regional factor. In Hungary, more circumstances have to be met, when there are changes in governmental policy, namely more strict and limiting public regulations (curfew or closing of services) or the opposite. The most credible, the fastest and widely available news source is the Government itself, thus, as people are more and more impatient, this lack of information is satisfied by the channels used by governmental organisations and PHOs. Daily and weekly updates of these regulations are available and is considered a prime time show, as its relative importance goes.

\subsection{Profession Credibility:}

Under profession credibility, the aim of the research was to gather professions or groups of professions that are considered important from a public communication perspective. Before the primary research, a list of professions were distributed to those partaking in the focused group interview. From it, they identified those profession or profession

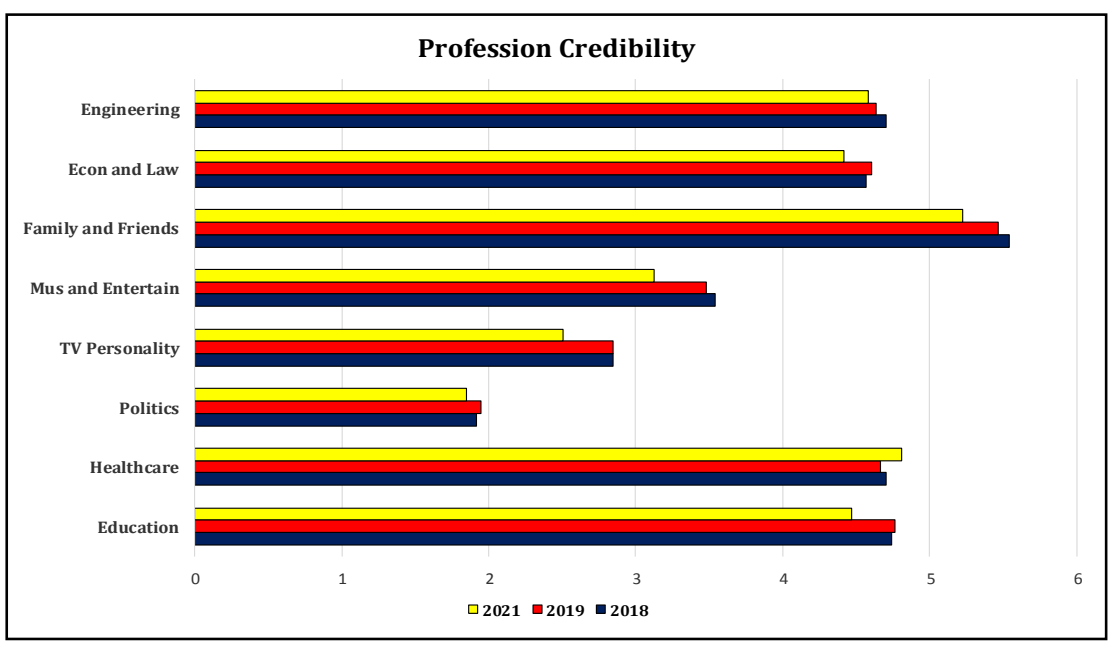

Figure 3. Averages of yearly Profession Credibility scores. Source: Based on primary research.

\begin{tabular}{|c|c|c|c|c|c|c|c|c|}
\hline YEAR & 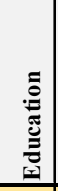 & 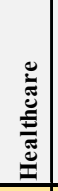 & $\begin{array}{l}: \\
: \\
:\end{array}$ & 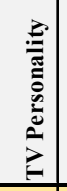 & 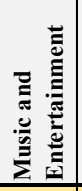 & 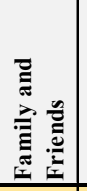 & 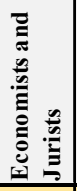 & 范 \\
\hline 2018 & 4,74 & 4,70 & 1,92 & 2,85 & 3,54 & 5,54 & 4,57 & 4,70 \\
\hline 2019 & 4,77 & 4,67 & 1,95 & 2,84 & 3,48 & 5,46 & 4,61 & 4,63 \\
\hline 2021 & 4,47 & 4,81 & 1,85 & 2,50 & 3,13 & 5,22 & 4,42 & 4,58 \\
\hline
\end{tabular}

Table 2. Deataled averages of yearly profession credibility scores. Source: Based on primary research. interviewees as highly capable and knowledgeable, a sort of respect and esteem is also identified within the healthcare field. This interpersonal relationship with these workers puts this industry in another dimension. Detailed averages can be found in Table 2.

An interesting finding of the group interview was the notion, that those working in politics, not necessarily only mean professional politicians or holders of governmental positions. The trust of those, deemed as working in a politically active environment, who may have an ulterior motive (opportunistic behaviour) will not be evaluated according to their profession, but will be considered as "politicians", thus public trust will be lower. The same is happening, when an official or PHO is deemed not professional enough, or not in live with public expectation (behaviour, conduct, attitude, communication skills). In this case, there was a general agreement, that this person has been given a position that is not based on merit, thus it's a political position. The opposite effect can also be achieved, when although someone is holding a public office, as long as the skills and merits of the person overweight the real or perceived benefits of the position, credibility will be judged according to the profession. The example of Györfi Pál was brought up, who is the Spokesman for the National Ambulance Service in Hungary since 2004. Regardless of the numerous political and leadership changes at that organisation, he holds the same position, and the credibility of the whole organisation is based on his work, attitude, and personal trust level in the eyes of the general public. 
In general those working in politics are viewed least favourably, followed by second worst television personalities, celebrities, and third musicians and entertainers. In these cases there was a general agreement, that these professionals are clearly "in it for the money", thus the motive is ulterior. As those working in the police and law enforcement, also disaster recovery personnel are more active in public communication, their trust has been evaluated. Law enforcement personnel are viewed in a slightly better light than the aforementioned three, having a score of 3,72. There wasn't a definite cause for this far from great position. Some of the interviewees identified negative sentiment and feelings, although not having any negative experiences directly with the police. In contrast, disaster recovery personnel, such as firefighters come in second place after family and friends with a score of 5,01. During the interview they were mostly associated with saving lives under dangerous and difficult circumstances, thus a similar or even greater esteem can be identified, than in the case of healthcare workers, with even lower levels of perceiver ulterior motives, because of the additional dangerous work environment.

\title{
7. Conclusions and Recommendations
}

The literature identified a line of factors that can negatively influence the credibility of governmental organisations and PHOs. This includes not being in line with public expectations, slow or incomplete information sharing, using inadequate communication channels, opportunistic behaviour, conduct and attitude (Jang and Baek, 2019; Carter, Thatcher and Wright, 2014; Busa et. al. 2015). These factors are correlating and can create synergies if used correctly in public information sharing.

According to the primary study the most trusted information is coming from Family and Friends. This category was the most important source of information regardless of credibility, preference or professional position. As this category uses a line of information sources, depending on their preferences, the following answers can be provided for the research questions:

a) The most trusted communication channels are online ones, followed by privately owned television, than classical channels such as radio or television. The public least prefers social media and governmentally owned or operated television channels. In case of social media and online channels the low entry barriers were identified as negative influencers, while in the case of governmental sources, the lack of two-way communication. In case of the preference scale, after Family and friends, online channels and social media was identified as the most favoured. This is caused by the relative ease and inexpensive nature of use, and quick information gathering and sharing. No other channel is capable of the quick and two way responses and targeted data search possibilities that online channels and social media ones have. In this aspect, although some positive changes are present, governmental channels are the least preferred.

b) The participants of the primary research clearly identified different groups of professions according to trust. Healthcare workers and those professions affiliated with knowledge clearly have an edge, with disaster management workers the having the beast scores because of the affiliated risks. The research also identified credibility being effected by the real or presumed benefits of the position and ulterior motives, thus regardless of their "civil profession" politicians will be distrusted.

c) In line with the literature and research, it is recommended that rather than political figures or holders of governmental positions, spokespersons and holders of credible professions should distribute information. Opinion leaders in general (for eg. celebrities) have a clear advantage when examining source power because of their large follower base, but in case of trust that is determined by source prestige, they are not favoured by the public. In cases of emergencies, focus should be on other credible people. In line with credibility and preferences, although classical channels are more favoured than online ones, because of the ease of use, even giver lower credibility scores, an extension and clear supervision and focus should be provided to them. Truly effective PHO and public service communication challenges fake news, is readily available and is in line with the preferences.

\section{References:}

Bridgman et. al. (2020) The causes and consequences of COVID-19 misperceptions: Understanding the role of news and social media, The Harvard Kennedy School Misinformation Review. June 2020, Volume 1, Special Issue on COVID19 and Misinformation

\section{Busa et. al (2015) Trust-building through Social Media Communications in Disaster Management, Companion, May.}

\author{
Carter, L. Thatcher, J. B. and Wright, R. (2014) Social Media and Emergency Management: Exploring State and Local \\ Tweets, 2014 47th Hawaii International Conference on System Science
}


Chan, K. K. and Misra, S. (1990) Characteristics of the Opinion Leader: A New Dimension, Journal of Advertising, Vol. 19, No. 3, pp. 53-60.

Crain, M. and Nadler, A. (2019) Political Manipulation and Internet Advertising Infrastructure, Journal of Information Policy, Vol. 9, pp. 370-410

ECDC (2012) Communication on immunisation - Building trust, Report for the European Centre for Disease Prevention and Control - Technical Document

Elsend, M. (2006) Source Credibility Dimensions in Marketing Communication-A Generalized Solution, Journal of Empirical Generalisations in Marketing Science, Vol. 10. January, pp. 01-33

Eurostat (2019) Digital economy and society statistics - households and individuals - Internet Access of Households, Online, available from: https://ec.europa.eu/eurostat/statistics-

explained/index.php?title=Digital_economy_and_society_statistics_-_households_and_individuals, Accessed: 2021.03.28.

Goldsmith, R. E. Lafferty, B. A. and Newell, S. J. (2000) The Impact of Corporate Credibility and Celebrity Credibility on Consumer Reaction toAdvertisements and Brands, Journal of Advertising, Vol. 29, No. 3 (Autumn), pp. 43-54

Gnambs, T. (2019) Opinion leadership types or continuous opinion leadership traits? International Journal of Psychology, Vol. 54, No. 1, pp. 88-92

Harlow, S. (2013) It was a "Facebook revolution": Exploring the meme-like spread of narratives during the Egyptian protests, Revista de Comunicación 12. pp. 59-82

Heideker, S. and Steul-Fischer, M. (2017) The Effects of Message Framing and Ad Credibility on Health Risk Perception, Journal of Research and Management, Vol. 39. Jahrg., H. 2, pp. 49-64

Hollensen, S. (2011) Global Marketing, Fifth Edition, Financial-Times Prentice Hall, UK

Keegan , J. W. and Green, M. C. (2011) Global Marketing, Sixth Edition, Pearson Education Limited, USA

Kyungeun Jang \& Young Min Baek (2019) When Information from Public Health Officials is Untrustworthy: The Use of Online News, Interpersonal Networks, and Social Media during the MERS Outbreak in South Korea, Health Communication, 34:9, 991-998, DOI: 10.1080/10410236.2018.1449552

Lemon, K. N., \& Verhoef, P. C. (2016) Understanding customer experience throughout the customer journey, Journal of marketing, 80(6), 69-96.

Maathuis, O. Rodenburg, J. and Sikkel, D. (2004) Credibility, Emotion or Reason, Corporate Reputation Review, Vol. 6, No. 4, pp. 333-345

Marcos-García, S, Alonso-Muñoz, L. and López-Meri, A. (2020) Extending influence on social media: The behaviour of political talk-show opinion leaders on Twitter, Communication \& Society, Vol. 33(2), pp. 277-293.

Meyer, C., \& Schwager, A. (2007) Understanding customer experience, Harvard Business Review, 85(2), 116.

Midgley, D. E. and Dowling, R. G. (1978) Innovativeness: The Concept and its Measurement, Journal of Consumer Research, Issue. 4 (March), pp. 229-242.

Morgan R. M. and Hunt S. D. (1994) The Commitment-Trust Theory of Relationship Marketing, Journal of Marketing, Vol. 58, No. 3, pp. 20-38

Orosdy, B. and Dobó, R. (2018) Popularity and credibility of communication channels in Hungary in 2017, Conference Proceedings, EMOK 2018 international conference, Komárno, Slovakia (in: Józsa László, Korcsmáros Enikő, Seres Huszárik Erika (szerk.) (2018): A hatékony marketing - EMOK 2018 Nemzetközi Tudományos Konferencia konferenciakötete. Selye János Egyetem: Komárom. ISBN: 978-80-8122-2)

Rawson, A., Duncan, E., \& Jones, C. (2013) The truth about customer experience, Harvard Business Review, 91(9), 9098. 
Statista (2021) Most popular social networks worldwide as of January 2021, ranked by number of active users (in millions), Online, available from: https://www.statista.com/statistics/272014/global-social-networks-ranked-by-number-ofusers/ , Accessed: 2021.04.02

Schmidt, et. al (2016) Source Credibility in Tobacco Control Messaging, Tobacco Regulatory Science. 2(1). pp. 31-37

Tóth, T. (2009) Nemzetközi Marketing, Akadémia Kiadó, Budapest

Vigar-Ellis, D. Pitt, L. and Caruana, A. (2015) Does objective and subjective knowledge vary between opinion leaders and opinion seekers? Implications for wine marketing, Journal of Wine Research, Vol. 26, No. 4, pp. 304-318

Waszak, P. M. Waszak, W. K. and Kubanek, A. (2018) The spread of medical fake news in social media -The pilot quantitative study, Health Policy and Technology Vol. 07, pp. 115-118 